\title{
AS RELAÇÕES BRASIL/ESPANHA NA TRANSIÇÃO PARA O ESTADO NOVO
}

Sandra Maria Lubisco Brancato*

No presente trabalho se examina parte da correspondência da Embaixada espanhola no Rio de Janeiro entre outubro e dezembro de 1937 para o Ministério de Estado espanhol e para o Ministério de Relações Exteriores do Brasil.

Com a análise desta documentação se quer demonstrar que durante os meses anteriormente citados as relaçöes entre o governo espanhol e o brasileiro estiveram bastante abaladas.

As causas que explicam esta situação relacioam-se com a orientação então dada pelo governo brasileiro à sua política interna. Antes, no entanto, de examinar como a orientação da política interna brasileira terminou afetando as relações Brasil/Espanha é importante que se tenha presente o relato que a Embaixada espanhola no Rio de Janeiro fazia dos acontecimentos brasileiros e ainda como os interpretava. Assim se poderá entender com mais exatidão o estado das relaçōes Brasil/Espanha.

As Vésperas do Estado Novo na Correspondência da Embaixada Espanhola no Rio de Janeiro

A correspondência que interessa examinar aqui, arranca de 4 de outubro de 1937, quando Fernando Morales Llamas, Encarregado dos Negócios da Espanha no Brasil informa à seu governo que havia sido declarado novo "Estado de Guerra" neste país. Parte das consideraçōes que faz na ocasião, já se enquadram na temática 
que mais insistentemente será enfocada no conjunto da correspondência em questão: o relacionamento entre Getúlio Vargas e os integralistas e a atitude tomada pelo governo em relaçảo aos movimentos de agitação comunista supostamente existentes no Brasil.

Ao anunciar para a Espanha que um novo "Estado de Guerra" fora implantado no Brasil, Morales Llamas deixa muito claro que a situação do país era extremamente grave. Ao se referir que o período de excessão se estenderia por noventa dias, chama a atenção que era precisamente este tempo que faltava para as eleiçōes entăo fixadas para 3 de janeiro de 1938. Em sua opiniảo tal quadro era mais agravado ainda pelo fato de os integralistas serem simpáticos a eventuais medidas que fossem tomadas para garantir a prorrogação do mandato do Presidente. Para esta prorrogação, acrescentava Morales Llamas,

"no se ve otro camino que el de conseguir, en nombre de perturbaciones del orden, producidas o anunciadas, que se cree un estado de anormalidad constitucional, utilizable como base bien para la retirada de los candidatos democráticos que se disputan la sucecesión bien para la suspensión de las elecciones."1

Destacava ainda Morales Llamas que a comissão nomeada pelo presidente para coordenar a aplicação do "Estado de Guerra" no. Brasil estava constituída por elementos como o General Newton Cavalcanti e o Almirante Paes de Leme, ambos las personalidades mas caracterizadamente fascistas del Ejército y de la Marina. ${ }^{2}$ Acreditava que estas duas autoridades, junto com o terceiro elemento da Comissão - o Ministro do Interior Macedo Soares, imprimiam a los negócios públicos un sabor marcadamente fascista. Portanto concluía que a situação política do Brasil era de predomínio ostensible del elemento fascista cerca de los altos poderes del Estado. ${ }^{3}$

É também com grande riqueza de detalhes que Morales Llamas expöe em sua correspondência com o Ministro de Estado espanhol a ação desencadeada pelo governo brasileiro contra os supostos focos de agitação comunista que atuavam no Brasil. Passa muito claramente a idéia de que o governo brasileiro, sem muitos escrúpulos, taxava de comunista qualquer mobilização da oposição para assim justificar a dureza das medidas repressivas que pretendia aplicar. O governo, comentava Morales Llamas com indisfarsável ironia. 
agia contra el comunismo y lo que con este nombre se designe. Esta predisposição do govemo, segundo ainda a versâo de Morales Llamas, estava muito bem delineada nas declaraçōes feitas pelo Brigadeiro Paes de Lemos em entrevista concedida a jornalistas, onde teria afirmado: "en esta hor a quien no sea contra el comunismo, es comunista. ${ }^{4}$

No final de outubro, transcorrido praticamente um mês desde que Morales Llamas enviara a Espanha suas impressöes sobre as medidas repressivas adotadas pelo governo brasileiro, voltava a insistir:

"el confusionismo adrede que califica bajo el denominador de 'comunismo' a todos los matices del anti-fascismo y de la democracia o simplemente de la oposión al Gobierno, permite dirigir contra todos, sin distinción, la ofensiva gubernamental, que además fomenta cuanto puede una sensación de pánico que paralice cualquier reacción y al amparo del cual y para dar forma de legalidad a una instauración del fascismo en el poder, se prepara una reforma constitucional."

Apesar de Morales Llamas considerar inquestionável a existência de ligações entre Getúlio Vargas e os integralistas, não hesitava em sustentar também que a autoridade do Presidente pairava inabalável tanto sobre estes como sobre os demais grupos políticos. Assim acreditava que se Getúlio Vargas sentisse nas Forças Armadas o suficiente respaldo para fazer frente aos integralistas certamente voltaria as costas para seus aliados. Na eventualidade de tal ocorrer, comentava Morales Llamas,

"el actual Presidente, cuya ductilidad-maleabilidad, sería talvez más gráfico - política es maravillosa, vendría talvez a encontrar oportuno un cambio de postura que le transformase en dique contra las ambiciones integralistas y en paladín de la democracía." 5

O Estado Novo: primeiras impressões da Embaixada espanhola no Rio de Janeiro

Transcorridas mais de quarenta e oito horas do golpe de 10 
de novembro, apesar de pairarem algumas dúvidas sobre o rumo definitivo que Getúlio Vargas daria a política brasileira, ${ }^{6}$ Morales Llamas já alertava em sua correspondência com a Espanha que tudo indicava que a sorte do Partido Integralista iria mudar. Afirmava ainda que no Brasil muitos tinham como certo que Getúlio Vargas usara os integralistas mientras necesario, para luego pasar insencible pero fatalmente, a un plano secundario. ${ }^{7}$

Em pouco tempo esta versão dos fatos foi se confirmando para Morales Llamas que não deixava de registrar em ofício de 20 de novembro de 1937 que os integralistas começavam a se sentir desalentados ao perceberem, depois de 10 de novembro, que Getúlio Vargas procurava fortalecer su propia y personal autoridad, con el natural y consiguiente detrimento de la que aspiraban a conseguir aquellas fuerzas.

Paralelamente a estas informações Morales Llamas vai mostrando também a seu governo que Getúlio Vargas buscava, aos poucos, organizar o Estado a su personal punto de vista, que, si bien no está pautado por el credo fascista, tiene con él los puntos de contacto que no pueden faltar en todos los régimenes de fuerza. Neste esforço, salienta ainda, se vienen realizando algunos pases a la reserva y se prepara otros de cuantas figuras en el Ejército o en la Armada tienen alguna significación democrática.

Interessante observar que não passa desapercebido para o Encarregado de Negócios da Espanha as novas combinaçöes políticas que iam se organizando no Brasil, graças às manobras que partiam da própria Presidência. No Ejército, afirmava Morales Llamas, havia os

“completamente sometidos al Sr. Getúlio Vargas, (...) no pocos que entienden que su actuación debiera ser todavía mas derechista o fascista, y otros-pocos, porque se les va eliminando - que querrían, por el contrario, verlo mas inclinado hacia al democracia.",8

Em ofício de data anterior já havia escrito: "Getúlio Vargas va encontrando hoy simpatias en ciertos sectores de la opinión pública, que antes no ocultaban su prevención, al suponerlo de acuerdo con los camisas verdes." 9

Já no final de dezembro de 1937, a idéia que em definitivo Morales Llamas passa em seus ofícios para o Ministério de Estado espanhol é que o governo de Getúlio Vargas seria irremediavelmente 
pessoal e ditatorial. É com detalhes que descreve as medidas repressivas que seguem sendo tomadas contra os integralistas, com o objetivo de desarticular qualquer mobilização que planejasem. ${ }^{10}$ Aparece com especial destaque a informação de que General Newton Cavalcanti, um dos homens de maior força e prestígio durante a aplicação do último "Estado de Guerra", caíra em total descrédito por atrapalhar agora os planos de Getúlio Vargas. O General Cavalcanti, comenta Morales Llamas,

"días pasados escribió al Presidente protestando de la nueva postura antiintegralista del Gobierno y solicitando ser relevado del mando de la Primera División (Capital), a lo que el Señor Getúlio Vargas contestó pasandolo a la reserva."11

Ao terminar o ano de 1937, para Morales Llamas o poder de Getúlio Vargas estava solidificado. $O$ presidente graças a sua imensa capacidade de manobra e persuação, fora aos poucos se sobrepondo a todos, movendo com habilidade os fios condutores da política nacional. ${ }^{12}$

\section{Reflexos da Política de Getúlio Vargas nas Relaçōes Brasil/Espanha}

As duas situações que marcaram o momento de transição para o Estado Novo - a perseguição aos comunistas e as tendências fascistas do governo - que são insistentemente referidas na correspondência de Morales Llamas conforme se viu, serão afinal responsáveis pelo abalo das boas relações até então existentes entre os governos espanhol e brasileiro. Em 23 de outubro de 1937 o Encarregado de Negócios da Espanha escreve este significativo ofício:

"Hasta tal punto se está extremando la gratuita hipótesis de que nuestro gobierno constitucional y democrático tiene un caracter 'comunista', y que sus adeptos, por lo tanto, han de serlo también, que la gran mayoría, de los españoles que hasta la fecha venían mas o menos intensamente mostrando su ideal gobernamental y contribuyendo o ayudarlo con su aporte material o con su propaganda, se ven reducidos a una total inacción, 
y, así y todo, no exentos de la desconfianza y aún de la persecucion de la policía."13

A evolução dos fatos iria demonstrar que efetivamente as autoridades brasileiras procuravam reprimir cada vez mais toda a atividade política dos republicanos espanhóis no Brasil. Assim, por exemplo, nas instruçōes passados pelo executor do "Estado de Guerra" aos jornais paulistas se pode ler:
"Prohibir a publicação de notícias - textos ou gravuras - elogiando o regime soviético ou homem deste regime (políticos militares, diplomatas, etc.) ou a publicação de victorias obtidas por tropas que defendem regimes bolchevistas, como o do governo de Valencia, na Hes- panha."14

Morales Llamas, como representante oficial da Espanha republicana no Brasil, não podia ficar insensível a tal atitude. Seu protesto formal foi encaminhado ao Ministério de Relações Exteriores do Brasil e, interessa particularmente observar o rigor de seu texto quando se refere a "notoria injusticia que se comete por quien aplica el calificativo de bolchevique al Gobierno a mi Pais." ${ }^{15}$ No mesmo ofício o Encarregado de Negócio manifesta também sua estranheza ante o fato do governo brasileiro manter relaçōes oficiais com o governo da Espanha republicana e ao mesmo tempo "prohibir la divulgación de victorias militares de um gobierno amigo, [o da Espanha republicana ], cuyo único objetivo es el de mantener la autoridad y retablecer el orden jurídico universalmente aceptado, contra un nucleo de militares sublevados."

Contudo o que se observa é que as medidas de retalhamento em relação a Espanha republicana seguiram sendo autorizadas. Em ofício encaminhado ao Ministério de Assuntos Exteriores do Brasil a 18 de novembro de 1937 Morales Llamas protesta de forma veemente contra o fechamento do Centro Republicano espanhol de Porto Alegre, bem como contra a prisão de vários associados. O referido ofício procura também, com inusitada clareza, mudar a imagem que o governo brasileiro tinha dos republicanos espanhóis. A certa altura do ofício se pode ler.

“...el caso de Porto Alegre no es único. Mas o menos intensamente, en otras localidades de diferentes Esta- 
dos del Brasil, notase idéntica prevención de las autoridades locales contra elementos españoles absolutamente ajenos a cualquier actividad subversiva y contra los cuales despierta inexplicable recelo el que publicamente, con la franqueza del que practica un acto lícito y loable, se muestran adeptos a la causa de la legalidad de mi Pais, que es precisamente la del orden, perturbado por una sublevación de algunos militares (...)[ que ] tienen fatalmente que despertar en el alma de todos los buenos españoles - aun de los que residen mas apartados del lugar de la tragedia - la protesta y el natural impulso de agruparse para fortalecer con su apoyo moral y con el aporte de su concurso, al Gobiemo de la República, que en su espíritu se identifica indisolublemente con el de España."

Chama atenção, no citado ofício, a preocupação de Morales Llamas em afirmar que os republicanos punidos eram "elementos españoles absolutamente ajenos a cualquier actividad subversiva." Esta afirmação conflita com informaçōes anteriores passadas a Espanha pelo próprio Morales Llamas. Em ofício de 4 de octubre de 1937 havia escrito que estando crescendo a influência integralista junto ao governo brasileiro era muito possível que tal circunstância viesse a criar "serio embarazo a la libre manifestación de los numerosos elementos que dentro del Brasil simpatizan con la justa causa de la legalidad española, y que, precisamente ahora, empezaban a articularse eficientemente."

A certeza da prática política exercida pelos espanhóis republicanos em seu centros e a evidente ligaçâo que o governo brasileiro fazia entre eles e os comunistas explicam, certamente, que as medidas repressivas contra os republicanos continuassem em pleno vigor. Assim, conforme relação enviada por Morales Llamas a Espanha, se pode enumerar as seguintes medidas: fechamento do Comitê Central de Propaganda da Espanha Republicana com sede em Sāo Paulo, "el mas eficaz instrumento de ayuda al Gobierno español que funcionaba en el Brasil"; a detenção do diretor da Gaceta Hispana, "el único periódico español y gubernista del Brasil"; o fechamento do Centro Republicano de Santos; e finalmente a detenção de diversas pessoas do Rio de Janeiro ligadas ao Centro Republicano desta cidade. ${ }^{16}$

$\mathrm{O}$ encaminhamento dado pelas autoridades brasileiras a estas 
e outras questões que envolviam os republicanos espanhóis agravavam dia a dia as relaçōes que já eram tensas entre a Espanha e o Brasil. Esta conclusão se impõe na medida em que se observa que o Encarregado de Negócios da Espanha não cansava de prọtestar cada vez com mais dureza ante as medidas que tomavam as autoridades brasileiras contra os defensores do governo republicano espanhol, lembrando justamente que o Brasil mantinha relações oficiais amistosas com este governo. As autoridades brasileiras apesar de terem "demonstrado siempre su espiritu altamente comprensivo y la mejor disposición para escuchar los casos" 17 não muaram de orientação. ${ }^{18}$ Por outro lado, quando se tratava da propaganda política organizada pelos nacionalistas espanhóis o governo brasileiro se mostrava bastante tolerante mesmo depois da instauração do Estado Novo, durante os meses de novembro e dezembro de 1937, quando os integralistas já enfrentavam sérias represálias.

Em 18 de novembro de 1937 Morales Llamas reclamava ao Ministro de Relações Exteriores do Brasil medidas contra a apresentação no Teatro Municipal do Rio de Janeiro de um espetáculo organizado pelo grupo chamado Falange Tradicionalista y de las J.O.N.S. (Juntas de Ofensivas Nacional Sindicalista), em benefício da campanha de inverno da Guerra civil espanhola. Apesar de o representante espanhol alegar que o auxílio buscado pelo citado grupo favorecia " a la rebelión armada que combate al Gobierno le gítimo" o espetáculo terminou sendo autorizado. Foram autorizadas também conferências organizadas pelos nacionalistas que eram amplamente divulgadas em seus jornais que circulavam sem a menor censura.

"El pasado sábado un sujeto de nada recomendables antecedentes, que ahora esta al servicio de los elementos facciosos españoles residentes en San Pablo, dió una conferencia, ampliamente anunciada, en la residencia de los Padres Agustinianos de aquella capital; y, al día seguiente, en el local del Club Portugal, que funciona en el predio Martilelli, se realizó una reunión, también en la prensa convocada, 'para fundar la Sociedad nacionalista Española'. Ante este fato o protesto foi contundente: 'Vuestra Exelencia no dejará de comprender la extrañeza con que presencio y con que mi Gobierno ha de conocer estas facilidades a los enemigos de la legalidad, precisamente cuando permane- 
cem cerrados, por imposición de las autoridades locales - de las cuales hasta la fecha no me ha sido posible conocer las razones que expliquen su conducta - Centros Republicano Españoles..."19

Como se vê são muitas as evidências que demonstram o deplorável estado em que se encontravam as relações Brasil/Espanha no final de 1937. Durante 1938 e nos anos subseqüentes a atitude de Getúlio Vargas frente aos espanhóis, tanto republicanos como nacionalistas, sofreu algumas alterações ao sabor das conveniências do momento. Basta lembrar, por exemplo, que nos anos quarenta, quando gradativamente o Brasil vai se alinhando aos Estados Unidos da América do Norte, o governo franquista passará a sofrer uma série de represálias do govemo brasileiro que em parte seräo responsávêis por novas tensões que marcarão, então, o relacionamento entre a Espanha e o Brasil.

NOTAS

1 Archivo del Ministerio de Asuntos Exteriores - Madri. Archivo Renovado: Brasil - Información Política (época roja). Legajo R.999, Expediente 12. Fernando Morales Llamas ao Ministro de Estado espanhol, Rio de Janeiro, 4 de outubro de 1937. Nas notas seguintes, quando nâo constar o contrário, a identificaçâo dos documentos coincide com a presente indicação.

${ }^{2} E_{m}$ ofício de 9/10/1937, Morales Llames já afirmara: "las ligaciones del General Newton Cavalcanti con el integralismo (fascismo brasileño) son del domínio público". (Leg. R. 999, Exp. 12).

330/10/1937. Leg. R. 999, Exp. 13.

$49 / 10 / 1937$.

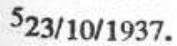

${ }^{6} \mathrm{Em}$ nota a seu governo Morales Llamas escreveu: "Ya transcurridas mas de 48 horas aun no puede asegurarse cual sea el camino que se va a seguir, y a ello contribuye poderosamente la especial idiosincrasia del Sr. Getulio Vargas, político sutil y que acostumbra a orientarse exclusivamente por sus proprias aspiraciones". (Leg. R 999, Exp. 13 - 13/11/1937).

7 Ibidem.

${ }^{8}$ Leg. R. 999, Exp. 13 - 27/11/1937. 
${ }^{9}$ Leg. R. 999. Exp. $13-20 / 11 / 1937$.

${ }^{10} \mathrm{Em}$ ofício de Morales Llamas de 31/12/1937 se pode ler: "Después de apoyarse en los fascistas, para llevar al extremo mas riguroso la campaña de combate a cuanto pudiese tener el mas leve cariz liberal, se vuelve ahora contra los propios fascistas; primero, disolviendo ese como todos los demás partidos políticos, después, saliendo al paso, con otro decreto, a la maniobra que pretendia reorganizar esa agrupación bajo el disfraz de una sociedad cultural y, en fin, estimulando las pesquisas polićacas que cada día con más empeño descubren depósitos de armas y lugares de irradiación de propaganda clandestina. Asi se va desarticulando el integralismo (Fascismo), siguiendo la misma política que comenzó por ir poco a poco apartando de todos los puestos de responsabilidad, en el ejército, marina y administración pública a los mas señalados partidarios del sistema". (Leg. R. 999, Exp. 13).

\section{${ }^{11}$ Ibidem.}

${ }^{12}$ Cf. Leg. R. 999, Esp. 13, ofício de 31/12/1937.

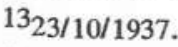

1429/10/1937. Transcrição para o Ministro de Estado espanhol de Nota enviada ao Ministro de Relaçōes Exteriores do Brasil.

-15 Ibidem.

${ }^{16}$ Cf. Leg. R. 999, Exp. 13, ofício de 27/11/1937.

\section{17/12/1937.}

${ }^{18} \mathrm{Em}$ ofício ao seu governo, Morales Llamas, deixa bem claro a difícil situação em que se encontrava, graças à atitude assumida pelo governo brasileiro: "sin gran fé en el resultado de la gestión, pero considerando que siempre se contribuirá con ello a evitar que el mal se acentue, continuo enviando al Ministerio de Relaciones Exteriores protestas por cuantos casos llegan a mi conocimiento que revelan la mala disposición de espfritu que en las esferas oficiales del Pais existe contra la causa de la legalidad española y la mucha labor de zapa llevada a cabo por elementos al servicio de los facciosos, en el Brasil. (20/12/1937).

$19_{17 / 12 / 1937 .}$

*Pontifícia Universidade Católica do Rio Grande do Sul Departamento de História CEP - 90.620 - Porto Alegre - RS 